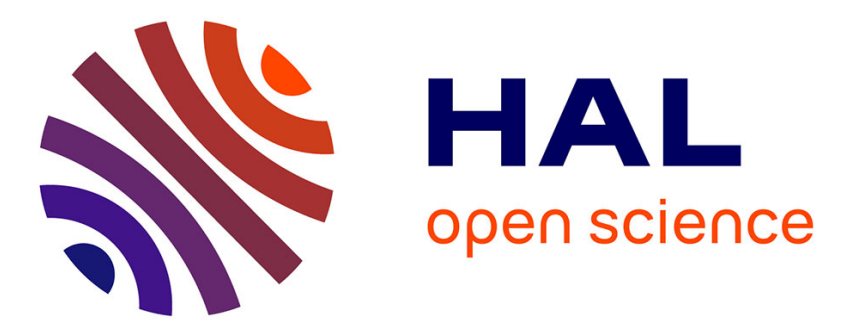

\title{
Rôle des phosphodiestérases des nucléotides cycliques dans la compartimentation subcellulaire de l'AMP cyclique des myocytes cardiaques
}

Delphine Mika, Jérôme Leroy, Grégoire Vandecasteele, Rodolphe Fischmeister

\section{- To cite this version:}

Delphine Mika, Jérôme Leroy, Grégoire Vandecasteele, Rodolphe Fischmeister. Rôle des phosphodiestérases des nucléotides cycliques dans la compartimentation subcellulaire de l'AMP cyclique des myocytes cardiaques. Biologie Aujourd'hui, 2012, 206 (1), pp.11-24. 10.1051/jbio/2012003 . hal02940230

\author{
HAL Id: hal-02940230 \\ https://hal.science/hal-02940230
}

Submitted on 16 Sep 2020

HAL is a multi-disciplinary open access archive for the deposit and dissemination of scientific research documents, whether they are published or not. The documents may come from teaching and research institutions in France or abroad, or from public or private research centers.
L'archive ouverte pluridisciplinaire HAL, est destinée au dépôt et à la diffusion de documents scientifiques de niveau recherche, publiés ou non, émanant des établissements d'enseignement et de recherche français ou étrangers, des laboratoires publics ou privés. 


\title{
Rôle des phosphodiestérases des nucléotides cycliques dans la compartimentation subcellulaire de l'AMP cyclique des myocytes cardiaques
}

\author{
Delphine Mika, Jérôme Leroy, Grégoire Vandecasteele, Rodolphe Fischmeister \\ Inserm UMR-S 769 - LabEx LERMIT, F-92296 Châtenay-Malabry, France \\ Université Paris-Sud, Faculté de Pharmacie, 5, Rue J.-B. Clément, F-92296 Châtenay-Malabry \\ Cedex, France.
}

Auteur correspondant: Rodolphe Fischmeister, rodolphe.fischmeister@inserm.fr

Reçu le 25 novembre 2011

\begin{abstract}
Résumé - La voie de l'AMP cyclique (AMPc) joue un rôle majeur dans la régulation neurohormonale de la fonction cardiaque. Les travaux effectués ces dernières années ont montré que ce second messager n'est pas uniformément distribué à l'intérieur des myocytes cardiaques, et que cette compartimentation est nécessaire pour la définition des signaux AMPc générés par des récepteurs distincts au niveau de la membrane plasmique. La localisation des signaux AMPc est liée à celle des adénylate-cyclases, responsables_de sa synthèse, mais aussi à sa diffusion dans le cytoplasme. La diffusion de l'AMPc peut être limitée par des structures intracellulaires mais aussi et surtout par les phosphodiestérases (PDE), qui sont à l'origine de sa dégradation. Cette revue fait le point sur le rôle des PDE dans la formation de microdomaines dynamiques d'AMPc impliqués dans la spécificité des hormones agissant sur le cœur.
\end{abstract}

Mots clés - Régulation neuro-hormonale cardiaque / AMP cyclique / phosphodiestérases / compartimentation / insuffisance cardiaque

Abstract - Role of cyclic nucleotide phosphodiesterases in the cAMP compartmentation in cardiac cells

In the light of the knowledge accumulated over the years, it becomes clear that intracellular cAMP is not uniformly distributed within cardiomyocytes and that cAMP compartmentation is required for adequate processing and targeting of the information generated at the membrane. Localized cAMP signals may be generated by interplay between discrete production sites and restricted diffusion within the cytoplasm. In addition to specialized membrane structures that may limit cAMP spreading, degradation of the second messenger by cyclic nucleotide phosphodiesterases (PDEs) appears critical for the formation of dynamic microdomains that confer specificity of the response to various hormones. This review summarizes the main findings that support the cAMP compartmentation hypothesis in cardiac cells, with a special emphasis on PDEs. The respective roles of the four main cardiac cAMP-PDE families (PDE1 to PDE4) in the organization of cAMP microdomains and hormonal specificity in cardiac cells are reviewed. The evidence that these PDEs are modified in heart failure is summarized, and the implication for the progression of the disease is discussed. Finally, the potential benefits that could be awaited from the manipulation of specific PDE subtypes in heart failure are presented. 
Keywords - Cardiac neurohumoral regulation / cAMP / phosphodiesterases / compartmentation / heart failure

\section{Abréviations}

AC, adénylate-cyclase

AKAP, A kinase anchoring protein

AMPc, AMP cyclique

$\beta$-AR, récepteur $\beta$-adrénergique

CEC, couplage excitation-contraction

EP-R, récepteur aux prostaglandines

FRET, Fluorescence Resonance Energy Transfer

GLP-1, glucagon-like peptide-1

Glu-R, récepteur au glucagon

$\mathrm{HCN}$, hyperpolarization activated cyclic nucleotide

IBMX, 3-isobutyl-1-méthylxanthine

IC, insuffisance cardiaque

Iso, isoprénaline

LTCC, canal calcique de type $\mathrm{L}$

MyBP-C, protéine $\mathrm{C}$ de liaison à la myosine

PDE, phosphodiestérase

PGE1, prostaglandine E1

PKA, protéine-kinase dépendante de l'AMPc

PLB, phospholamban

$\mathrm{RCPG}_{\mathrm{s}}$, récepteur couplé aux protéines $\mathrm{G}$

$\mathrm{RS}$, réticulum sarcoplasmique

RyR, récepteur à la ryanodine

TnI, troponine I 


\section{Introduction}

Dans le cœur, la voie de l'AMPc régule la contraction, la relaxation, l'automaticité, le métabolisme et l'expression génique. Elle est majoritairement impliquée dans la régulation sympathique de la fonction cardiaque (Fischmeister et al., 2006). Sous l'effet d'une libération de noradrénaline des terminaisons nerveuses sympathiques, ou d'adrénaline des glandes surrénales, les récepteurs $\beta$-adrénergiques ( $\beta$-AR) sont activés, entraînant une stimulation, via les protéines $G$ stimulatrices $G_{s}$, de la synthèse du second messager intracellulaire, l'AMPc par les adénylatecyclases (AC). Classiquement, les effets cardiaques de l'AMPc sont attribués à l'activation de la protéine-kinase dépendante de l'AMPc (PKA) qui phosphoryle plusieurs protéines clés du couplage excitation-contraction cardiaque (CEC), parmi lesquelles le canal calcique de type L (LTCC), le phospholamban (PLB), le récepteur à la ryanodine (RyR), la troponine I (TnI) et la protéine $\mathrm{C}$ de liaison à la myosine (MyBP-C) (Bers, 2002). Mais la PKA n'est pas la seule cible de l'AMPc, qui active également le facteur d'échange Epac (de Rooij et al., 1998) impliqué dans l'hypertrophie cardiaque (Morel et al., 2005; Métrich et al., 2008) et les canaux ioniques «pacemaker» de type HCN (hyperpolarization activated cyclic nucleotide gated channels) (Barbuti \& DiFrancesco, 2008).

De nombreuses observations étayent l'hypothèse d'une compartimentation de l'AMPc dans les cellules cardiaques (Steinberg \& Brunton, 2001). Une première évidence de cette compartimentation vient du constat que l'activation des $\beta$-AR par les catécholamines et des récepteurs aux prostaglandines (EP-R) par la prostaglandine E1 (PGE1) augmente de façon similaire l'AMPc mais conduit à des effets différents sur des cœurs isolés perfusés (Corbin et al., 1977 (a et/ou b ?) ; Keely, 1979). Ceci serait lié à l'existence de deux isozymes de PKA (PKAI et PKAII) dans le myocarde, qui diffèrent par la nature de leurs sous-unités régulatrices RI et RII et par leur distribution: PKAI est principalement soluble alors que PKAII est associée à la fraction particulaire (Corbin \& Keely, 1977; Corbin et al., 1977(a et/ou b ?)). Alors que la stimulation des $\beta$-AR active la PKA dans les deux compartiments et conduit à l'activation des enzymes glycogénolytiques et à la phosphorylation de la TnI, la stimulation des EP-R augmente l'activité PKA dans la fraction soluble uniquement et ne stimule pas le métabolisme du glycogène ni l'activité contractile ou la phosphorylation de la TnI (Buxton \& Brunton, 1983; Hayes et al., 1979). Les récepteurs $\beta_{1}-\mathrm{AR}$ et $\beta_{2}$-AR sont à l'origine de réponses différentes dans les cardiomyocytes isolés. Contrairement à la stimulation des $\beta_{1}$-AR qui conduit à la phosphorylation des LTCC, RyR, PLB, TnI et MyBP-C, la signalisation $\beta_{2}$-AR est restreinte à la membrane plasmique et à la régulation des LTCC, et donc dépourvue d'effet lusitrope ? positif dans les myocytes ventriculaires de rat (Xiao \& Lakatta, 1993; Xiao et al., 1994; Calaghan et al., 1998). Des résultats similaires sont observés chez le chien, bien que dans ce cas la stimulation $\beta_{2}$-AR accélère également la relaxation (Altschuld et al., 1995; Kuschel et al., 1999). Cependant, d'autres études réalisées dans des cardiomyocytes de rat montrent que la stimulation $\beta_{2}-\mathrm{AR}$ active la phosphorylation par la PKA du PLB et donc accélère la relaxation, sans augmenter la phosphorylation de la TnI et de la phosphorylase a (Bartel et al., 2003). En plus des $\beta$-AR et des EP-R, le myocyte cardiaque exprime plusieurs autres récepteurs couplés aux protéines $G_{s}$ $\left(\mathrm{RCPG}_{\mathrm{s}}\right)$, par exemple les récepteurs au glucagon (Glu-R) et les récepteurs au GLP-1 (glucagonlike peptide-1). Leur activation conduit également à une production d'AMPc, cependant les effets métaboliques et contractiles des Glu-R ne sont pas maintenus (tachyphylaxie) (Farah, 1983; Juan-Fita et al., 2004) alors que la stimulation des GLP1-R induit un effet inotrope modeste en dépit d'une augmentation du niveau d'AMPc total comparable à celle des $\beta$-AR (Vila 
Petroff et al., 2001). Récemment, des approches d'électrophysiologie et d'imagerie, permettant la mesure d'AMPc à un niveau subcellulaire, ont confirmé que ces différents récepteurs, les $\beta_{1-}$ $\mathrm{AR}, \beta_{2}-\mathrm{AR}, \mathrm{EP}-\mathrm{R}$, Glu-R et GLP1-R, génèrent des signaux AMPc distincts qui régulent ainsi différemment les cibles de la PKA comme le LTCC, le PLB et la TnI (Rochais et al., 2006; Warrier et al., 2007; Di Benedetto et al., 2008; Agarwal et al., 2011). Grâce à l'utilisation de sondes AMPc basées sur le FRET (Fluorescence Resonance Energy Transfer) fusionnées aux domaines de dimérisation et d'ancrage des sous-unités régulatrices RI $\alpha$ et RII $\beta$ de la PKA, Di Benedetto et al. (2008) ont montré que l'AMPc généré par l'isoprénaline (Iso, un agoniste des $\beta$ AR) est préférentiellement augmenté dans le compartiment intracellulaire comprenant la PKARII, alors qu'une stimulation des GLP1-R, Glu-R et PGE1-R conduit à une plus large augmentation de l'AMPc dans le compartiment comprenant la PKA-RI. Ces augmentations sont accompagnées de la phosphorylation de PLB, TnI et $\beta_{2}-\mathrm{AR}$ induite par l'Iso, mais pas par la PGE1. L'ensemble de ces résultats indique que la cellule est capable de discriminer différents stimuli agissant via le même second messager et soulève la question du mécanisme impliqué.

Un premier élément de réponse réside dans le fait que les différents acteurs de la voie AMPc sont localisés au niveau de régions discrètes de la cellule. Dans les cellules ventriculaires, l'invagination de la membrane plasmique forme un réseau de tubules transverses, appelés tubules $\mathrm{T}$, dont la principale fonction est de synchroniser les relargages de $\mathrm{Ca}^{2+}$ pendant le CEC (Brette \& Orchard, 2003). En plus des protéines impliquées dans les mouvements calciques telles que le LTCC (Gao et al., 1997; Hulme et al., 2003), l'échangeur sodium/calcium (Yang et al., 2002) et l'ATPase calcique de la membrane plasmique (Despa et al., 2003; Chase \& Orchard, 2011), de nombreux autres composants de la voie AMPc sont enrichis dans les tubules $\mathrm{T}$ : les protéines $\mathrm{G}_{\mathrm{s}}$ (Laflamme \& Becker, 1999), les AC de type 5 et 6 (Gao et al., 1997; Laflamme \& Becker, 1999), les PDE de type 3 et 4 (Lugnier et al., 1993; Mongillo et al., 2004), les sous-unités régulatrices de la PKA et les protéines d'ancrage AKAPs (A kinase anchoring proteins) (Yang et al., 1998). Du fait de leur faible niveau d'expression et de l'absence d'anticorps spécifiques, la localisation des $\mathrm{RCPG}_{\mathrm{s}}$ dans les cardiomyocytes est délicate. En combinant la technique d'imagerie basée sur le FRET et de microscopie de conductance ionique à balayage, Nikolaev et al. (2010) ont récemment mis en évidence une localisation des $\beta_{2}-\mathrm{AR}$ au niveau des tubules $\mathrm{T}$ dans les myocytes ventriculaires sains, contrairement aux $\beta_{1}$-AR qui sont distribués sur l'ensemble de la membrane plasmique. Les cavéoles constituent également des microdomaines d'un grand intérêt pour la transduction des signaux AMPc (Ostrom et al., 2001). En effet, on retrouve au niveau des cavéoles membranaires les récepteurs $\beta_{1}$-AR co-localisés avec les AC5/6 (Ostrom et al., 2000, 2001). Les récepteurs $\beta_{2}$-AR semblent exclusivement présents dans les cavéoles et régulent les canaux LTCC (Rybin et al., 2003; Balijepalli et al., 2006; Calaghan et $a l ., 2008)$. Alors que les protéines $\mathrm{G}_{\mathrm{s}}$ sont distribuées sur l'ensemble de la surface sarcolemmale, les protéines $\mathrm{G}_{\mathrm{i}}$ sont strictement localisées dans les cavéoles (Steinberg \& Brunton, 2001; Rybin et al., 2003). Ainsi, la colocalisation au niveau des cavéoles des $\beta_{2}$-AR avec les protéines $\mathrm{G}_{\mathrm{i}}$ joue un rôle important dans la compartimentation des réponses $\beta_{2}$-AR. Récemment, il a été montré qu'une altération des cavéoles entraîne une augmentation des réponses $\beta_{2}-\mathrm{AR}$ et de la phosphorylation du PLB et de la TnI se traduisant par une accélération de la relaxation (Calaghan et al., 2008). Alors que la sous-unité RII de la PKA est cavéolaire, les récepteurs muscariniques M2 et la sous-unité RI semblent exclus des cavéoles (Steinberg \& Brunton, 2001).

En plus des microdomaines décrits ci-dessus, les composants de la voie de signalisation AMPc sont organisés en complexes multiprotéiques, augmentant ainsi l'efficacité et la spécificité de la cascade de transduction. Les AKAPs jouent un rôle essentiel dans ces arrangements. Elles 
forment une large famille de protéines de plus de 50 membres dont la principale fonction est de localiser la PKA à proximité de ses substrats, assurant ainsi la phosphorylation préférentielle d'un nombre limité de protéines cibles (Scott \& Santana, 2010). Elles servent également de protéines d'échafaudage pour les autres composants de la signalisation AMPc, dont les phosphatases 1 et 2 (Marx et al., 2000, 2002), le facteur d'échange Epac (Dodge-Kafka et al., 2005), les AC5/6 (Bauman et al., 2006) et la PDE4D3 (Dodge et al., 2001; Dodge-Kafka et al., 2005; Terrenoire et al., 2009).

Cette organisation fine des composants de la voie AMPc apparait nécessaire mais n'est pas suffisante pour expliquer la spécificité des hormones qui activent cette voie. En effet, étant donné son faible poids moléculaire, l'AMPc généré par la stimulation d'un récepteur donné devrait diffuser très rapidement dans la cellule, et activer l'ensemble de ses cibles. En fait, s'il n'en est pas ainsi, c'est que la diffusion de l'AMPc est limitée. L'existence de barrières physiques créées par des structures membranaires spécialisées a été proposée pour expliquer les différences de concentration d'AMPc sous la membrane plasmique et dans le cytoplasme de cellules HEK293 stimulées par la PGE1, même si une preuve expérimentale reste à apporter (Rich et al., 2000). Cependant, d'autres mécanismes permettent de restreindre la diffusion du second messager : le pouvoir tampon des sous-unités régulatrices de la PKA (Saucerman et al., 2006; Nikolaev et al., 2010) et, surtout, son hydrolyse par les PDE qui joue un rôle crucial dans la formation de microdomaines dynamiques d'AMPc (Fischmeister et al., 2006; Scott \& Santana, 2010).

\section{PDE et compartimentation de l'AMPc}

A ce jour, 11 familles de PDE incluant 20 gènes et environ 50 isoformes ont été répertoriées sur la base de leur séquence primaire en acide aminés et de leurs propriétés cinétiques et régulatrices (Conti \& Beavo, 2007). Elles présentent toutes un domaine catalytique d'environ 270 acides aminés, localisé dans la portion C-terminale de la protéine. Ce domaine présente 20 à $25 \%$ d'homologie de séquence en acides aminés d'une famille à une autre. La région $\mathrm{N}$-terminale, qui constitue le domaine régulateur de l'enzyme, est caractéristique de chacune des familles. Ce domaine régule l'activité catalytique et la localisation subcellulaire de la protéine, et est composé, selon la famille envisagée, de domaines de liaison au complexe $\mathrm{Ca}^{2+} /$ calmoduline, de domaines de liaison aux petites molécules telles que les nucléotides cycliques (domaines GAF : cGMP-activated PDE, Adenylate cyclase, FhlA), de régions UCR (upstream conserved regions), de domaines PAS (nom de 3 protéines connues pour contenir ce domaine : period, arylhydrocarbon receptor nuclear translocator, single minded), de sites de phosphorylation, de dimérisation, ou d'adressage (Conti \& Beavo, 2007). Certains domaines régulateurs ont été identifiés en C-terminal et semblent contenir des sites de phosphorylation et de dimérisation (Mehats et al., 2002).

Au niveau cardiaque, on distingue classiquement 4 familles de PDE responsables de la dégradation de l'AMPc: PDE1, PDE2, PDE3 et PDE4. Alors que la PDE1 et la PDE2 hydrolysent l'AMPc et le GMPc, la PDE3 hydrolyse préférentiellement l'AMPc et la PDE4 est spécifique pour l'AMPc. La PDE1 est activée par le complexe $\mathrm{Ca}^{2+} /$ calmoduline, la PDE2 et la PDE3 sont respectivement activée et inhibée par le GMPc et la PDE4 est activée par la PKA (Conti \& Beavo, 2007). La PDE1 est codée par 3 gènes $P D E 1 A-C$, la PDE2 par un gène $P D E 2 A$, la PDE3 par deux gènes $P D E 3 A-B$ et PDE4 par 4 gènes $P D E 4 A-D$. Les myocytes cardiaques expriment deux isoformes de PDE2A (Sonnenburg et al., 1991), trois isoformes de PDE3A 
(Wechsler et al., 2002) et plus de cinq isoformes de PDE4 codées par PDE4A, PDE4B et PDE4D (Kostic et al., 1997; Richter et al., 2005; Abi-Gerges et al., 2009). Une cinquième PDE, la PDE8A, hydrolyse spécifiquement l'AMPc et semble impliquée dans le contrôle du CEC cardiaque chez la souris (Patrucco et al., 2010). De nombreuses études ont été réalisées sur homogénats de cœurs ou sur cardiomyocytes isolés afin de déterminer l'activité des PDE. Alors que les quatre familles de PDE sont présentes dans le tissu cardiaque de mammifères, leur niveau d'expression dépend fortement de l'espèce considérée. Chez le rat et la souris, l'activité de la PDE4 représente $60 \%$ de l'activité totale d'hydrolyse de l'AMPc, alors que la PDE3 ne représente que 20 à 30\% et les PDE1 et PDE2 le reste (Georget et al., 2003; Xiang et al., 2005; Leroy et al., 2008; Richter et al., 2011). Les formes longues de PDE4 sont phosphorylées et activées par la PKA, augmentant ainsi la prévalence de cette famille (Sette \& Conti, 1996; Oki et al., 2000). Dans les cardiomyocytes de rat, ce rétrocontrôle négatif permet de limiter l'accumulation excessive d'AMPc lors d'une stimulation $\beta$-AR (Rochais et al., 2004; Leroy et al., 2008; Scott \& Santana, 2010). Dans le cœur de lapin, de cobaye et de hamster, la PDE1 prédomine, suivie de la PDE2 et la PDE3, alors que la PDE4 représente une plus faible activité (Reeves et al., 1987; Shahid et al., 1990; Masunaga et al., 2004). Chez l'homme, l'activité PDE4 ne représente que 10\% de l'activité PDE totale (Reeves et al., 1987; Shahid \& Nicholson, 1990; Masunaga et al., 2004; Richter et al., 2011) alors que les autres familles de PDE, PDE1, PDE2 et PDE3 sont responsables de la majorité de l'activité d'hydrolyse de l'AMPc (Hambleton et al., 2005; Vandeput et al., 2007; Richter et al., 2011).

Une des premières évidences de la contribution des PDE à la compartimentation intracellulaire de l'AMPc a été apportée par une étude réalisée sur des cœurs perfusés de cobaye. Les effets de l'Iso et de l'IBMX (3-isobutyl-1-méthylxanthine), un inhibiteur non sélectif des PDE, ou de la milrinone, un inhibiteur de la PDE3, ont été comparés. Alors que ces deux traitements augmentent l'AMPc intracellulaire et produisent des effets inotrope et lusitrope positifs, des différences dans le profil de phosphorylation par la PKA des protéines clés du CEC comme le PLB, la TnI et la MyBP-C ont été observées (Rapundalo et al., 1989). Ces résultats ont été attribués à une compartimentation subcellulaire de l'AMPc et des substrats de la PKA, due à une différence d'expression des PDE à la membrane et dans le cytosol (Weishaar et al., 1987). Dans les cardiomyocytes ventriculaires de chien, l'augmentation de l'AMPc contenu dans la fraction particulaire mais pas totale est corrélée à une augmentation de l'amplitude et des cinétiques de retour des transitoires calciques ? (Hohl \& Li, 1991). En réponse à une stimulation $\beta$-AR, environ $45 \%$ de l'AMPc total est présent dans la fraction particulaire mais cette fraction chute à moins de 20\% lorsqu'IBMX est ajouté à l'Iso, malgré une production d'AMPc 3 à 4 fois plus élevée. Ces résultats montrent que les PDE sont essentiellement présentes dans le cytoplasme, où elles préviennent l'accumulation excessive d'AMPc lors d'une activation des $\beta$ AR. Ces enzymes sont donc cruciales pour maintenir la spécificité des réponses $\beta$-AR en limitant la diffusion du second messager de la membrane vers le cytoplasme. La reconnaissance du caractère local de la régulation $\beta$-AR et du rôle des PDE dans ce phénomène a aussi été mise en évidence en utilisant un système de microperfusion permettant d'exposer les deux moitiés d'un myocyte cardiaque de grenouille à deux solutions externes différentes. Ce dispositif a permis de montrer qu'en l'absence d'IBMX, l'application d'Iso à une moitié de la cellule se traduit par une augmentation demi-maximale du courant calcique, correspondant à l'activation des canaux calciques situés sur la partie de la cellule exposée à l'agoniste $\beta$-AR. Si l'IBMX est ajouté à l'Iso sur une moitié de la cellule, la stimulation du courant calcique est fortement potentialisée car dans cette condition les canaux calciques présents au niveau de la partie non exposée peuvent 
être activés. Ces résultats suggèrent donc que les PDE sont importantes pour la définition de microdomaines locaux d'AMPc impliqués dans la régulation $\beta$-AR des LTCC (Jurevicius \& Fischmeister, 1996). Des études ultérieures utilisant des sondes FRET ratiométriques pour l'AMPc ont montré que sous stimulation $\beta$-AR, ce second messager augmente préférentiellement au niveau des lignes $Z$ des myocytes cardiaques, et que la diffusion de l'AMPc est limitée par l'activité des PDE (Zaccolo \& Pozzan, 2002; Nikolaev \& Lohse, 2006; Nikolaev et al., 2006). D'autres études, utilisant des canaux CNG (cyclic nucleotide gated channels) recombinants pour mesurer l'AMPc sous la membrane plasmique, ont identifié des couplages fonctionnels spécifiques entre différentes familles de PDE et différents récepteurs hormonaux couplés à $\mathrm{G}_{\mathrm{s}}$ ( $\beta_{1}$-Ars (s??), $\beta_{2}$-AR, PGE1-R et Glu-R) permettant aux cellules de générer des signaux AMPc spécifiques de chaque type de récepteur (Rochais et al., 2006).

\section{Rôle des différentes familles de PDE dans la compartimentation de l'AMPc}

L'utilisation d'inhibiteurs sélectifs des familles PDE2, PDE3 et PDE4 a permis d'évaluer la contribution de ces enzymes dans la compartimentation des voies de l'AMPc dans les myocytes cardiaques. Cependant, un inhibiteur sélectif des PDE1 n'étant pas disponible commercialement, le rôle de cette famille dans le cœur reste encore largement méconnu (Vandeput et al., 2007; Miller et al., 2009).

\subsection{Rôle de PDE2 et compartimentation de l'AMPc}

Dans les myocytes de grenouille et de rat, la PDE2 est présente préférentiellement dans les fractions microsomales (Simmons \& Hartzell, 1988; Mongillo et al., 2006), associée à des structures membranaires fonctionnelles comme la membrane plasmique, le réticulum sarcoplasmique (RS), l'appareil de Golgi ou l'enveloppe nucléaire (Lugnier, 2006). Bien que son activité soit relativement faible comparée aux autres PDE cardiaques, telles que les PDE3 et PDE4, sa présence au niveau de la membrane plasmique contribue à réguler l'activité des LTCC dans de nombreuses espèces dont l'Homme (Hartzell \& Fischmeister,1986; Hartzell \& Simmons, 1987; Fischmeister et al., 2005). Le rôle de la PDE2 dans la compartimentation des nucléotides cycliques a été examiné sur des cardiomyocytes de grenouille (Dittrich et al., 2001). Les auteurs ont montré qu'une stimulation de la guanylate cyclase soluble conduit à une forte diminution localisée d'AMPc au voisinage du LTCC, due à l'activation de la PDE2, mais seulement à une modeste diminution d'AMPc dans le reste de la cellule. Ceci s'expliquerait par l'existence d'un microdomaine où seraient compris les $\beta$-AR, les canaux LTCC et la PDE2 (Dittrich et al., 2001). Plus récemment, une étude sur des myocytes de rats nouveaux-nés a montré grâce à des sondes AMPc basées sur le FRET que les PDE2 limitent les signaux AMPc générés par une stimulation $\beta$-AR, limitant ainsi leur effet inotrope positif. Cet effet ferait intervenir les $\beta_{3}-A R s$ (s??) et la voie NO/GMPc (Mongillo et al., 2006). Les PDE2 sont également impliquées dans le contrôle des concentrations sous-membranaires de GMPc (Castro et al., 2006, 2010). Une étude récente a montré que lors d'une stimulation $\beta$-AR, les réponses AMPc mesurées par des senseurs FRET, localisés par les domaines d'ancrage des sous-unités RI $\alpha$ et RII $\beta$ de la PKA, sont modulées de façon opposée par le GMPc (Stangherlin et al., 2011). Dans les microdomaines correspondant à

RI $\alpha$, l'inhibition de la PDE3 par le GMPc est responsable d'une amplification des niveaux d'AMPc à l'Iso, tandis que dans les microdomaines correspondant à RII $\beta$, le GMPc stimule la PDE2, réduisant ainsi les niveaux d'AMPc. Des résultats similaires ont été obtenus en mesurant 
l'activité PKA dans ces compartiments, ainsi que la phosphorylation de cibles de la PKA en aval et la contraction cellulaire (Stangherlin et al., 2011).

\subsection{Rôle de PDE3 dans la compartimentation de l'AMPc}

Un rôle de la PDE3 dans la compartimentation de l'AMPc est prédit par sa distribution intracellulaire. De plus, puisque la PDE3 est inhibée par le GMPc, la production localisée de cet autre second messager participe à la régulation des signaux AMPc produits lors d'une stimulation $\beta$-AR, conduisant à des augmentations locales des niveaux d'AMPc (Stangherlin et al., 2011). La PDE3 est retrouvée dans les fractions cytoplasmiques et membranaires des myocytes cardiaques avec des différences importantes entre les espèces et les tissus (Muller et al., 1992 ; Lugnier, 2006). Par exemple, dans le cœur de chien l'activité PDE3 révélée dans la fraction membranaire apparaît être associée à la membrane du RS (Kauffman et al., 1986; Weishaar et al., 1987; Lugnier et al., 1993, 1999). Chez la souris, l'inhibition de la PDE3 conduit à une élévation de 1' AMPc et à une activation de la PKA localisées, menant à une augmentation de la phosphorylation du PLB (Kerfant et al., 2007). En revanche, chez le cobaye et le rat, la PDE3 est principalement présente dans la fraction soluble et ses inhibiteurs ont des effets plus modestes (Lugnier et al., 1993). Deux gènes codent pour deux sous-familles de PDE3, PDE3A et PDE3B. La PDE3A est exprimée dans le myocarde de rat, de chien, de cobaye et humain (Weishaar et al., 1987; Bethke et al., 1992; Wechsler et al., 2002; Abi-Gerges et al., 2009) et les deux sous-familles sont présentes dans les myocytes ventriculaires de souris (Patrucco et al., 2004). L'existence de trois isoformes de PDE3A dans le myocarde humain (Wechsler et al., 2002), localisées dans des compartiments différents de la cellule (Hambleton et al., 2005), contribue à la compartimentation de l'AMPc. La PDE3B, mise en évidence au niveau du cœur de souris, forme un complexe au niveau de la membrane sarcolemmale avec la PI3K $\gamma$ (Patrucco et al., 2004). Dans cette étude, les auteurs ont montré que la PI3K $\gamma$ n'active pas PDE3B via son activité de kinase mais lui sert plutôt de protéine d'ancrage au niveau d'un compartiment membranaire. Plus récemment, ces auteurs ont montré que la PI3K $\gamma$ ancre la PKA au niveau de sa région $\mathrm{N}$-terminale, permettant ainsi l'activation de la PDE3B par la PKA et la dégradation d'AMPc (Perino et al., 2011). Cependant, une étude contredit ce résultat en montrant que la PI3K $\gamma$ est uniquement nécessaire à l'activité de la PDE4, impliquée dans la dégradation de l'AMPc au voisinage de la SERCA (expliciter) mais pas dans l'environnement du LTCC (Kerfant et al., 2007).

\subsection{Rôle de PDE4 dans la compartimentation de l'AMPc}

Contrairement aux PDE2 et PDE3, la PDE4 est spécifique de l'AMPc et n'est pas régulée par le GMPc. Dans les cardiomyocytes ventriculaires de rat et de souris, la PDE4 n'a pas d'effet sur le l'AMPc basal mais devient cruciale pour hydrolyser l'AMPc généré par une stimulation $\beta$ AR (Mongillo et al., 2004; Rochais et al., 2004; Xiang et al., 2005; Nikolaev et al., 2006; Leroy et al., 2008) et pour le contrôle de la phosphorylation par la PKA des protéines clés du CEC telles que le LTCC (Verde et al., 1999; Leroy et al., 2008), le RyR2 (Lehnart et al., 2005) et le PLB (Kerfant et al., 2007). Une inhibition de la PDE4 potentialise donc fortement les effets inotropes d'une stimulation $\beta$-AR chez ces espèces (Katano \& Endoh, 1990, 1992). Cependant, bien que moins étudié, le rôle de la PDE4 apparaît plus modeste chez les gros mammifères et chez l'Homme. Dans l'oreillette humaine, les réponses inotropes à une stimulation $\beta$-AR sont 
principalement régulées par la PDE3 (Christ et al., 2006; Kaumann et al., 2007). In vivo, l'effet inotrope positif des inhibiteurs de PDE4 rapporté chez le chien est aboli par l'administration de $\beta$-bloquants, suggérant une action pré-synaptique sur la libération de noradrénaline (Weishaar et $a l ., 1987)$. La famille des PDE4 est codée par quatre gènes différents $P D E 4 A-D$, mais seulement $P D E 4 A, P D E 4 B$ et $P D E 4 D$ sont exprimés dans le tissu cardiaque (Kostic et al., 1997). De nombreux variants sont générés par épissage alternatif ou utilisation de différents promoteurs (Bolger et al., 2007). Jusqu'à maintenant, la plupart des études réalisées sur le cour ont porté sur le gène $P D E 4 D$, en particulier sur les formes longues : PDE4D3, PDE4D5, PDE4D8 et PDE4D9 (Richter et al., 2005).

Le rôle des isoformes PDE4A et PDE4B dans la régulation des niveaux d'AMPc et de la fonction cardiaque est moins bien connu. Leur activité a été détectée chez le rongeur et plus faiblement chez l'Homme (Richter et al., 2011). Cependant, la PDE4B régule les niveaux d'AMPc près de la membrane plasmique dans les cellules HEK293 (Terrin et al., 2006) et les fibroblastes embryonnaires de souris (Blackman et al., 2011) et une étude suggère que cette isoforme est importante pour la terminaison des signaux $\beta$-AR dans les cardiomyocytes néonataux (Mongillo et al., 2004). Dans une étude récente, réalisée sur les cardiomyocytes ventriculaires de souris, nous avons montré que les deux isoformes PDE4B et PDE4D sont associées au LTCC, mais que seule la PDE4B régule le courant calcique de type L (ICa,L) lors d'une stimulation $\beta$-AR. Dans les myocytes de souris invalidées pour le gène PDE4B (PDE4B ${ }^{-/-}$), l'augmentation de ICa,L par l'Iso conduit à une augmentation des transitoires calciques et de la contraction mais aussi à des augmentations spontanées de calcium intracellulaire pouvant expliquer la susceptibilité accrue aux arythmies ventriculaires observée chez les souris PDE4B ${ }^{-/-}$ lors de stimulation $\beta$-AR in vivo. Ces résultats soulignent l'importance d'une localisation stratégique des PDE4 pour assurer le contrôle du CEC cardiaque et des arythmies (Leroy et al., 2011).

La localisation subcellulaire des différentes isoformes de PDE4 est assurée par la région N-terminale unique qui constitue un véritable «code postal» (Baillie \& Houslay, 2005). Par exemple, la PDE4A1 contient un domaine de liaison aux lipides appelé TAPAS, qui présente une spécificité pour l'acide arachidonique permettant l'adressage de la PDE à des membranes cellulaires spécifiques (Baillie et al., 2002). Dans le cœur, la PDE4D3 est localisée dans la région sarcomérique des cardiomyocytes grâce à son ancrage à la myomégaline (Verde et al., 2001) et dans la région périnucléaire où elle s'associe à la mAKAP ou AKAP6 (Dodge et al., 2001). On la retrouve également au niveau de la dyade, où elle est associée aux RyR2 (Lehnart $e t$ al., 2005), et au sarcolemme, où elle est associée au canal potassique KCNQ1/KCNE1 (Terrenoire et al., 2009). Le compartiment d'AMPc localisé près du noyau contrôlerait le passage de la sous-unité catalytique de la PKA dans le noyau (Lugnier et al., 1993, 1999 ; Dodge et al., 2001) et donc la régulation génique. Ce complexe est intéressant parce qu'en plus de lier la PKA et la PDE4D3, la mAKAP lie également Epac1 et la kinase Erk5 (Dodge-Kafka et al., 2005). PKA, PDE4D3 et Epac1 répondent au second messager dans des gammes de concentrations différentes. Ainsi, la PKA est activée pour des concentrations de l'ordre de la centaine de $\mathrm{nM}$, alors que la PDE4D3 et Epac1 répondent à des concentrations de l'ordre du $\mu \mathrm{M}$. L'inactivation de ces dernières précèdera donc la reformation de l'holoenzyme PKA (DodgeKafka et al., 2005). De plus, la phosphorylation de PDE4D3 par la PKA sur la sérine 54 augmente son activité (Sette \& Conti, 1996; Richter et al., 2005) et sur la sérine 13 son affinité pour la mAKAP (Carlisle Michel et al., 2004), alors que sa phosphorylation par Erk5 sur la sérine 579 supprime son activité (Dodge-Kafka et al., 2005). Lorsque le facteur d'échange Epac1 
est activé par l'AMPc, il active Rapl qui supprime l'activation d'Erk5 et lève l'inhibition sur PDE4D3. L'existence de ce complexe apporte donc un contrôle spatial de l'activité de la PKA par son ancrage via la mAKAP, ainsi qu'une régulation temporelle par l'activité PDE située dans le voisinage immédiat (Dodge et al., 2001; Tasken \& Aandahl, 2004). Il est intéressant de noter que la PDE4D3 située au niveau du RyR2 est très diminuée dans l'insuffisance cardiaque humaine (Lehnart et al., 2005). Ces résultats soulignent donc l'importance des microdomaines d'AMPc et suggèrent la possibilité qu'une dérégulation de ces compartiments spécifiques puisse conduire à des états pathologiques.

Récemment, une étude a mis en évidence que la PDE4D3, comme la PKA et la phosphatase PP1, est recrutée au niveau du canal potassique via l'AKAP Yotiao ?? et contribue à la régulation du courant potassique IKs par l'AMPc (Terrenoire et al., 2009). Un autre exemple de complexe formé autour de PDE4 dans le cœur est celui formé par la PDE4D5 et la $\beta$-arrestine (Perry et al., 2002). Les $\beta$-arrestines sont des protéines d'échafaudage qui initient la désensibilisation des récepteurs $\beta_{2}$-AR par leur translocation du cytosol vers la membrane plasmique où elles se lient aux récepteurs. Des travaux récents ont montré que les $\beta$-arrestines peuvent former des complexes stables avec toutes les sous-familles de PDE4 mais que la PDE4D5 possède une région $\mathrm{N}$-terminale unique qui lui confère une interaction préférentielle avec les $\beta$-arrestines. L'activation des récepteurs $\beta_{2}$-AR entraîne la production d'AMPc et l'activation de PKA ancrée à l'AKAP-79 (Lynch et al., 2005). La PKA phosphoryle le $\beta_{2}$-AR ce qui permet le découplage de $\mathrm{G}_{\mathrm{s}}$ à $\mathrm{G}_{\mathrm{i}}$ et donc l'activation de Erk (Baillie et al., 2003). Le recrutement du complexe $\beta$-arrestine-PDE4D5 met un terme à la phosphorylation par la PKA du récepteur $\beta_{2}-\mathrm{AR}$, et prévient le passage vers un couplage du récepteur à la protéine $\mathrm{G}_{\mathrm{i}}$. $\mathrm{A}$ l'inverse, la perturbation de ce complexe augmente la phosphorylation du récepteur par la PKA, conduisant à des modifications importantes de ses fonctions (Baillie et al., 2003; Houslay \& Baillie, 2003).

Les PDE4D5, PDE4D8 et PDE4D9 interagissent directement ou via la $\beta$-arrestine avec les récepteurs $\beta$-AR dans les cardiomyocytes de rats néonataux (De Arcangelis et al., 2009; Richter et al., 2008). En conditions basales, les isoformes PDE4D8 et PDE4D9 sont préférentiellement associées aux récepteurs $\beta_{2}$-AR. La stimulation de ces récepteurs induit la dissociation de PDE4D9 du récepteur et le recrutement de PDE4D8 et PDE4D5 au niveau du récepteur activé. Ces associations complexes de PDE avec les récepteurs permettraient de définir des signaux AMPc et donc des réponses physiologiques spécifiques pour différentes stimulations hormonales (De Arcangelis et al., 2009).

\section{PDE et insuffisance cardiaque}

De nombreuses études ont mis en évidence une diminution de l'expression et/ou de l'activité des PDE dégradant l'AMPc dans plusieurs modèles d'hypertrophie et/ou d'insuffisance cardiaque (IC) : hamsters cardiomyopathes (Masunaga et al., 2004), cœurs insuffisants de chien (Smith et al., 1997 ; Sato et al., 1999), cœurs de rats (Abi-Gerges et al., 2009) et souris (Ding et $a l ., 2005 b$ ) soumis à une constriction aortique transverse, insuffisance cardiaque humaine (Ding et al., 2005a). Inversement, l'activité des PDE hydrolysant le GMPc telles que PDE1A, PDE2 et PDE5 semble accrue en hypertrophie ( Nagendran et al., 2007 ; Miller et al., 2009; Mokni et al., 2010). Parce que les PDE sont cruciales pour orchestrer la signalisation AMPc dans les cardiomyocytes (Fischmeister et al., 2006), une diminution de l'activité PDE pourrait conduire à un défaut de compartimentation de l'AMPc et donc à la perte de spécificité de ces signaux 
intracellulaires. L'inhibition de la PDE3, initialement décrite comme stratégie thérapeutique pour traiter l'IC, a été associée à une augmentation du taux de mortalité des patients insuffisants (Yan et al., 2007). Ces effets délétères pourraient s'expliquer par l'induction via CREB (cAMP response element-binding) du facteur pro-apoptotique ICER (Inducible Cyclic AMP Early Repressor) lorsque la PDE3 est inhibée (Ding et al., 2005a, 2005b). La perte de l'isoforme PDE3B à la membrane plasmique conduit également à des dommages cardiaques importants dans un modèle animal de surcharge chronique de pression (Patrucco et al., 2004). La diminution des isoformes de PDE4 pourrait conduire à un remodelage électrophysiologique en augmentant l'activité du LTCC au cours de l'hypertrophie, comme rapporté dans les myocytes ventriculaires insuffisants humains (Schroder et al., 1998; Chen et al., 2002;) ou à un raccourcissement de la durée du potentiel d'action en augmentant la phosphorylation par la PKA du canal potassique KCNQ1/KCNE1 (Terrenoire et al., 2009). De plus, chez la souris déficiente pour le gène $P D E 4 D$, l'hyperphosphorylation de RyR2 par la PKA conduit à une libération anormale de $\mathrm{Ca}^{2+}$ $\mathrm{du}$ RS, augmentant l'incidence des arythmies induites par l'exercice et favorisant le développement d'une cardiomyopathie dilatée dans les souris âgées (Lehnart et al., 2005). Comme montré ci-dessus, la PDE4D3 fait de plus partie du complexe incluant ERK5 et Epac1, deux protéines impliquées dans la croissance des cardiomyocytes (Dodge-Kafka et al., 2005; Morel et al., 2005).

\section{Perspectives}

Les connaissances accumulées à ce jour indiquent clairement que l'AMPc n'est pas distribué uniformément dans les cardiomyocytes, et que les PDE jouent un rôle essentiel dans ce confinement. La compartimentation de cette voie de signalisation est d'une importance majeure dans l'adressage spécifique d'une information générée à la membrane. L'hypothèse de la compartimentation de l'AMPc est basée sur deux postulats principaux (Steinberg \& Brunton, 2001). Toutes les molécules de PKA ne phosphorylent pas l'ensemble des substrats potentiels dans la cellule. Cette condition est vérifiée par l'existence des protéines AKAPs qui lient spécifiquement la PKA à ses effecteurs (Dodge-Kafka et al., 2006). Le second postulat est que l'AMPc généré par une AC donnée n'active pas toutes les PKA cellulaires. Cette condition peut être vérifiée par la localisation spécifique des PDE près des AC et des effecteurs de l'AMPc. Élucider les détails de cette organisation subcellulaire nécessiterait des modèles moléculaires, cellulaires et animaux, pour explorer : 1) les signalosomes AMPc générés par AC5 et AC6, les deux principales AC exprimées dans les myocytes ventriculaires adultes dont la fonction spécifique n'est pas encore connue (Willoughby \& Cooper, 2007); 2) le rôle des isoformes de PDE dans la délimitation des compartiments de l'AMPc qui contrôlent spécifiquement la fonction des effecteurs du CEC cardiaque ; et 3) le rôle de l'architecture cellulaire. L'hypothèse de la compartimentation doit également être explorée dans d'autres types cellulaires tels que les cellules musculaires lisses où l'AMPc contrôle la vasodilatation, la croissance et la prolifération cellulaire (Stork \& Schmitt, 2002).

Une autre perspective concerne la physiopathologie cardiaque et les différences entre les effets chroniques et aigus de l'AMPc. Bien que la voie de l'AMPc soit bénéfique sur la fonction cardiaque en aigu, et soit essentielle pour les effets chronotrope (augmentation de la fréquence cardiaque), inotrope (augmentation de la force de contraction) et lusitrope positifs (accélération de la relaxation) lors de la réponse «fight-or-flight », l'activation chronique de cette voie induit généralement une croissance hypertrophique et une dysfonction ventriculaire (Osadchii, 2007), 
conduisant au développement de l'IC (Movsesian, 2004). Les altérations de la voie de l'AMPc pendant l'hypertrophie et l'insuffisance cardiaque ont été bien décrites mais les mécanismes exacts responsables de la cardiotoxicité de cette voie ne sont pas complètement élucidés. Comme mentionné plus haut, l'activité des PDE est diminuée lors de l'hypertrophie cardiaque chez le rat. Ceci conduit-il à une désorganisation de la compartimentation AMPc ? À la perte de la spécificité hormonale? À des effets cardiotoxiques de l'AMPc ? Ceci contribue-t-il au développement de l'IC?

Enfin, une stratégie thérapeutique peut-elle émerger de ce concept de compartimentation de l'AMPc ? Un grand nombre d'études ont montré que les PDE sont des composants intégraux de complexes macromoléculaires organisés autour de protéines cibles spécifiques, telles que le LTCC (Jurevicius \& Fischmeister, 1996; Fischmeister et al., 2006; Leroy et al., 2011) ou le RyR (Lehnart et al., 2005). L'activation de ces PDE pourrait donc réduire la phosphorylation chronique par la PKA de ces protéines, réduire la concentration en calcium intracellulaire et prévenir la survenue d'arythmies et la mort subite. A l'inverse, une inhibition de la PDE3A-136 associée au PLB de la membrane du RS pourrait permettre de préserver les flux de $\mathrm{Ca}^{2+}$ intracellulaire et la contractilité chez les patients traités par $\beta$-bloquants, sans effet proarythmique concomitant (Wechsler et al., 2002; Movsesian \& Bristow, 2005). Afin de tester cette hypothèse, des modèles animaux surexprimant ou invalidés pour une isoforme spécifique de PDE sont nécessaires, pour permettre l'exploration de leurs fonctions cardiaques dans des conditions normales ou de stress. De telles expériences permettront de tester si la restauration de la voie AMPc peut stopper le développement de l'insuffisance cardiaque ou même restaurer la fonction cardiaque.

\section{Remerciements}

Les auteurs remercient Monsieur Patrick Lechêne pour son aide à la mise en forme de ce texte. Ce travail a été soutenu par la fondation Leducq (cycAMP 06CV02) et l'Agence Nationale de la Recherche, financement 2010 BLAN 113901.

\section{Références}

Abi-Gerges A., Richter W., Lefebvre F., Matéo P., Varin A., Heymes C., Samuel J.-L., Lugnier C., Conti M., Fischmeister R., Vandecasteele G., Decreased expression and activity of cAMP phosphodiesterases in cardiac hypertrophy and its impact on $B$-adrenergic cAMP signals. Circ Res, 2009, 105, 784-792.

Agarwal S.R., MacDougall D.A., Tyser R., Pugh S.D., Calaghan S.C., Harvey R.D., Effects of cholesterol depletion on compartmentalized cAMP responses in adult cardiac myocytes. J Mol Cell Cardiol, 2011, 50, 500-509.

Altschuld R.A., Starling R.C., Hamlin R.L., Billman G.E., Hensley J., Castillo L., Fertel R.H., Hohl C.M., Robitaille P.M.L., Jones L.R., Xiao R.P., Lakatta E.G., Response of failing canine and human heart cells to beta(2)-adrenergic stimulation. Circulation, 1995, 92, 1612-1618.

Baillie G.S., Houslay M.D., Arrestin times for compartmentalised cAMP signalling and 
phosphodiesterase-4 enzymes. Curr Op Biol, 2005, 17, 1-6.

Baillie G.S., Huston E., Scotland G., Hodgkin M., Gall I. , Peden A.H., MacKenzie C., Houslay E.S., Currie R., Pettitt T.R., Walmsley A.R., Wakelam M.J., Warwicker J., Houslay M.D., TAPAS-1, a novel microdomain within the unique $\mathrm{N}$-terminal region of the PDE4A1 cAMP-specific phosphodiesterase that allows rapid, $\mathrm{Ca}^{2+}$-triggered membrane association with selectivity for interaction with phosphatidic acid. J Biol Chem, 2002, 277, 28298-28309.

Baillie G.S., Sood A., McPhee I., Gall I., Perry S.J., Lefkowitz R.J., Houslay M.D., $\beta$ Arrestin-mediated PDE4 cAMP phosphodiesterase recruitment regulates $\beta$-adrenoceptor

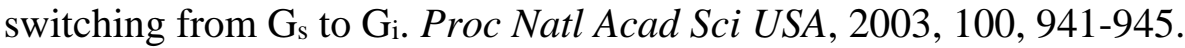

Balijepalli R.C., Foell J.D., Hall D.D., Hell J.W., Kamp T.J., Localization of cardiac L-type $\mathrm{Ca}^{2+}$ channels to a caveolar macromolecular signaling complex is required for $\beta_{2-}$ adrenergic regulation. Proc Natl Acad Sci USA, 2006, 103, 7500-7505.

Barbuti A., DiFrancesco D., Control of cardiac rate by "funny" channels in health and disease. Ann New York Acad Sci, 2008, 1123, 213-223.

Bartel S., Krause E.G., Wallukat G., Karczewski P. (). New insights into ß2-adrenoceptor signaling in the adult rat heart. Cardiovasc Res, 2003, 57, 694-703.

Bauman A.L., Soughayer J., Nguyen B.T., Willoughby D., Carnegie G.K., Wong W., Hoshi N., Langeberg L.K., Cooper D.M., Dessauer C.W., Scott J.D., Dynamic regulation of cAMP synthesis through anchored PKA-adenylyl cyclase V/VI complexes. Mol Cell, 2006, 23, 925-931.

Bers D.M.,Cardiac excitation-contraction coupling. Nature, 2002, 415, 198-205.

Bethke T., Eschenhagen T., Klimkiewicz A., Kohl C., von der Leyen H., Mehl H., Mende U., Meyer W., Neumann J., Rosswag S., Schmitz W., Scholz H., Starbatty J., Stein B., Wenzlaff H., Döring V., Kalmar P., Haverich A., Phosphodiesterase inhibition by enoximone in preparations from nonfailing and failing human hearts. Arzneimittel-Forsch, $1992,42,437-445$.

Blackman B.E., Horner K., Heidmann J., Wang D., Richter W. , Rich T.C., Conti M., PDE4D and PDE4B function in distinct subcellular compartments in mouse embryonic fibroblasts. J Biol Chem, 2011, 286, 12590-12601.

Bolger G.B., Conti M., Houslay M.D., Cellular functions of PDE4 enzymes. In: Cyclic Nucleotide Phosphodiesterases in Health and Disease, S. Francis, J.A. Beavo, M.D. Houslay (Eds), 2007, CRC Press, Taylor \& Francis Group, Chapter 6, 99-130.

Brette F., Orchard C., T-tubule function in mammalian cardiac myocytes. Circ Res, 2003, 92, 1182-1192.

Buxton I.L.O., Brunton L.L., Compartments of cyclic AMP and protein kinase in mammalian cardiomyocytes. J Biol Chem, 1983, 258, 10233-10239.

Calaghan S., Kozera L., White E., Compartmentalisation of cAMP-dependent signalling by caveolae in the adult cardiac myocyte. J Mol Cell Cardiol, 2008, 45, 88-92.

Calaghan S.C., White E., Colyer J., Co-ordinated changes in cAMP, phosphorylated 
phospholamban, $\mathrm{Ca} 2+$ and contraction following beta-adrenergic stimulation of rat heart. Pflügers Arch, 1998, 436, 948-956.

Carlisle Michel J.J., Dodge K.L., Wong W., Mayer N.C., Langeberg L.K., Scott J.D., PKAphosphorylation of PDE4D3 facilitates recruitment of the mAKAP signalling complex. Biochem J, 2004, 381, 587-592.

Castro L.R.V., Verde I., Cooper D.M.F., Fischmeister R., Cyclic guanosine monophosphate compartmentation in rat cardiac myocytes. Circulation, 2006, 113, 2221-2228.

Castro L.R.V., Schittl J., Fischmeister R., Feedback control through cGMP-dependent protein kinase contributes to differential regulation and compartmentation of cGMP in rat cardiac myocytes. Circ Res, 2010, 107, 1232-1240.

Chase A., Orchard C.H., Ca efflux via the sarcolemmal Ca ATPase occurs only in the ttubules of rat ventricular myocytes. J Mol Cell Cardiol, 2011, 50, 187-193.

Chen X., Piacentino V.I., Furukawa S., Goldman B., Margulies K.B., Houser S.R., L-type Ca ${ }^{2+}$ channel density and regulation are altered in failing human ventricular myocytes and recover after support with mechanical assist devices. Circ Res, 2002, 91, 517-524.

Christ T., Engel A., Ravens U., Kaumann A.J., Cilostamide potentiates more the positive inotropic effects of (-)-adrenaline through $\beta_{2}$-adrenoceptors than the effects of (-)noradrenaline through $\beta_{1}$-adrenoceptors in human atrial myocardium. NaunynSchmiedebergs Arch Pharmacol, 2006, 374, 249-253.

Conti M., Beavo J.A., Biochemistry and physiology of cyclic nucleotide phosphodiesterases: Essential components in cyclic nucleotide signaling. Ann Rev Biochem, 2007, 76, 481-511.

Corbin J.D., Keely S.L., Characterization and regulation of heart adenosine 3':5'monophosphate-dependent protein kinase isozymes. J Biol Chem, 1977a, 252, 910-918.

Corbin J.D., Sugden P.H., Lincoln T.M., Keely S.L., Compartmentalization of adenosine 3':5'-monophosphate and adenosine 3':5'-monophosphate-dependent protein kinase in heart tissue. J Biol Chem, 1977b, 252, 3854-3861.

De Arcangelis V., Liu R., Soto D., Xiang Y., Differential association of phosphodiesterase 4D isoforms with $\beta_{2}$-adrenoceptor in cardiac myocytes. J Biol Chem, 2009, 284, 3382433832.

de Rooij J., Zwartkruis F.J., Verheijen M.H., Cool R.H., Nijman S.M., Wittinghofer A., Bos J.L., Epac is a Rap1 guanine-nucleotide-exchange factor directly activated by cyclic AMP. Nature, 1998, 396, 474-477.

Despa S., Brette F., Orchard C.H., Bers D.M., Na/Ca exchange and Na/K-ATPase function are equally concentrated in transverse tubules of rat ventricular myocytes. Biophys $J, 2003$, 85, 3388-3396.

Di Benedetto G., Zoccarato A., Lissandron V., Terrin A., Li X., Houslay M.D., Baillie G.S., Zaccolo M., Protein kinase A type I and type II define distinct intracellular signaling compartments. Circ Res, 2008, 103, 836-844.

Ding B., Abe J., Wei H., Huang Q., Walsh R.A., Molina C.A., Zhao A., Sadoshima J., Blaxall B.C., Berk B.C., Yan C., Functional role of phosphodiesterase 3 in cardiomyocyte 
apoptosis: implication in heart failure. Circulation, 2005a, 111, 2469-2476.

Ding B., Abe J., Wei H., Xu H., Che W., Aizawa T., Liu W., Molina C.A., Sadoshima J., Blaxall B.C., Berk B.C. , Yan C., A positive feedback loop of phosphodiesterase 3 (PDE3) and inducible cAMP early repressor (ICER) leads to cardiomyocyte apoptosis. Proc Natl Acad Sci USA, 2005b, 102, 14771-14776.

Dittrich M., Jurevicius J., Georget M., Rochais F., Fleischmann B.K., Hescheler J., Fischmeister R., Local response of L-type $\mathrm{Ca}^{2+}$ current to nitric oxide in frog ventricular myocytes. J Physiol, 2001, 534, 109-121.

Dodge K.L., Khouangsathiene S., Kapiloff M.S., Mouton R., Hill E.V., Houslay M.D., Langeberg L.K., Scott J.D., mAKAP assembles a protein kinase A/PDE4 phosphodiesterase cAMP signaling module. EMBO J, 2001, 20, 1921-1930.

Dodge-Kafka K.L., Soughayer J., Pare G.C., Carlisle Michel J.J., Langeberg L.K., Kapiloff M.S., Scott J.D. The protein kinase A anchoring protein mAKAP co-ordinates two integrated cAMP effector pathways. Nature, 2005, 437, 574-578.

Dodge-Kafka K.L., Langeberg L., Scott J.D., Compartmentation of cyclic nucleotide signaling in the heart: the role of A-kinase anchoring proteins. Circ Res, 2006, 98, 9931001 .

Farah A.E., Glucagon and the heart. Exp Pharmacol, 1983, 53, 553-609.

Fischmeister R., Castro L., Abi-Gerges A., Rochais F., Vandecasteele G., Species- and tissue-dependent effects of NO and cyclic GMP on cardiac ion channels. Comp Biochem Physiol, Part A, Mol Integr Physiol, 2005, 142, 136-143.

Fischmeister R., Castro L.R.V., Abi-Gerges A., Rochais F., Jurevičius J., Leroy J., Vandecasteele G. Compartmentation of cyclic nucleotide signaling in the heart: The role of cyclic nucleotide phosphodiesterases. Circ Res, 2006, 99, 816-828.

Gao T.Y., Puri T.S., Gerhardstein B.L., Chien A.J., Green R.D., Hosey M.M., Identification and subcellular localization of the subunits of L-type calcium channels and adenylyl cyclase in cardiac myocytes. J Biol Chem, 1997, 272, 19401-19407.

Georget M., Mateo P., Vandecasteele G., Lipskaia L., Defer N., Hanoune J., Hoerter J., Lugnier C., Fischmeister R., Cyclic AMP compartmentation due to increased cAMPphosphodiesterase activity in transgenic mice with a cardiac-directed expression of the human adenylyl cyclase type 8 (AC8). FASEB J, 2003, 17, 1380-1391.

Hambleton R., Krall J., Tikishvili E. , Honeggar M., Ahmad F., Manganiello V.C., Movsesian M.A., Isoforms of cyclic nucleotide phosphodiesterase PDE3 and their contribution to cAMP-hydrolytic activity in subcellular fractions of human myocardium. $J$ Biol Chem, 2005, 280, 39168-39174.

Hartzell H.C., Fischmeister R. Opposite effects of cyclic GMP and cyclic AMP on $\mathrm{Ca}^{2+}$ current in single heart cells. Nature, 1986, 323, 273-275.

Hartzell H.C., Simmons M.A., Comparison of effects of acetylcholine on calcium and potassium currents in frog atrium and ventricle. J Physiol, 1987, 389, 411-422.

Hayes J.S., Brunton L.L., Brown J.H., Reese J.B., Mayer S.E., Hormonally specific 
expression of cardiac protein kinase activity. Proc Natl Acad Sci USA, 1979, 76, 15701574.

Hohl C.M., Li Q, Compartmentation of cAMP in adult canine ventricular myocytes Relation to single-cell free $\mathrm{Ca}^{2+}$ transients. Circ Res, 1991, 69, 1369-1379.

Houslay M.D., Baillie G.S., The role of ERK2 docking and phosphorylation of PDE4 cAMP phosphodiesterase isoforms in mediating cross-talk between the cAMP and ERK signalling pathways. Biochem Soc Trans, 2003, 31, 1186-1190.

Hulme J.T., Lin T.W., Westenbroek R.E., Scheuer T., Catterall W.A., ß-adrenergic regulation requires direct anchoring of PKA to cardiac $\mathrm{Ca}_{v} 1.2$ channels via a leucine zipper interaction with A kinase-anchoring protein 15. Proc Natl Acad Sci USA, 2003, 100, 13093-13098.

Juan-Fita M.J., Vargas M.L., Kaumann A.J., Hernandez Cascales J., Rolipram reduces the inotropic tachyphylaxis of glucagon in rat ventricular myocardium. Naunyn-Schmiedebergs Arch Pharmacol, 2004, 370, 324-329.

Jurevicius J., Fischmeister R., cAMP compartmentation is responsible for a local activation of cardiac $\mathrm{Ca}^{2+}$ channels by $\beta$-adrenergic agonists. Proc Natl Acad Sci USA, 1996, 93, 295299.

Katano Y., Endoh M. Differential effects of Ro 20-1724 and isobutylmethylxanthine on the basal force of contraction and beta-adrenoceptor-mediated response in the rat ventricular myocardium. Biochem Biophys Res Com, 1990, 167, 123-129.

Katano Y., Endoh M., Effects of a cardiotonic quinolinone derivative Y-20487 on the isoproterenol-induced positive inotropic action and cyclic AMP accumulation in rat ventricular myocardium: comparison with rolipram, Ro 20-1724, milrinone, and isobutylmethylxanthine. J Cardiovasc Pharmacol, 1992, 20, 715-722.

Kauffman R.F., Crowe V.G., Utterback B.G., Robertson D.W., LY195115: a potent, selective inhibitor of cyclic nucleotide phosphodiesterase located in the sarcoplasmic reticulum. Mol Pharmacol, 1986, 30, 609-616.

Kaumann A., Semmler A.B., Molenaar P., The effects of both noradrenaline and CGP12177, mediated through human $\beta_{1}$-adrenoceptors, are reduced by PDE3 in human atrium but PDE4 in CHO cells. Naunyn-Schmiedebergs Arch Pharmacol, 2007, 375, 123-131.

Keely S.L., Prostaglandin E1 activation of heart cAMP-dependent protein kinase: apparent dissociation of protein kinase activation from increases in phosphorylase activity and contractile force. Mol Pharmacol, 1979, 15, 235-245.

Kerfant B.G., Zhao D., Lorenzen-Schmidt I., Wilson L.S., Cai S., Chen S.R., Maurice D.H., Backx P.H., PI3KY is required for PDE4, not PDE3, activity in subcellular microdomains containing the sarcoplasmic reticular calcium ATPase in cardiomyocytes. Circ Res, 2007, 101, 400-408.

Kostic M.M., Erdogan S., Rena G., Borchert G., Hoch B., Bartel S., Scotland G., Huston E., Houslay M.D., Krause E.G., Altered expression of PDE1 and PDE4 cyclic nucleotide phosphodiesterase isoforms in 7-oxo-prostacyclin-preconditioned rat heart. J Mol Cell Cardiol, 1997, 29, 3135-3146. 
Kuschel M., Zhou Y.Y., Spurgeon H.A., Bartel S., Karczewski P., Zhang S.J., Krause E.G., Lakatta E.G., Xiao R.P., ß2-adrenergic cAMP signaling is uncoupled from phosphorylation of cytoplasmic proteins in canine heart. Circulation, 1999, 99, 2458-2465.

Laflamme M.A., Becker P.L., $\mathrm{G}_{\mathrm{s}}$ and adenylyl cyclase in transverse tubules of heart: implications for cAMP-dependent signaling. Am J Physiol Heart Circ Physiol, 1999, 277, H1841-H1848.

Lehnart S.E., Wehrens X.H.T., Reiken S., Warrier S., Belevych A.E., Harvey R.D., Richter W., Jin S.L.C., Conti M., Marks A., Phosphodiesterase 4D deficiency in the ryanodine receptor complex promotes heart failure and arrhythmias. Cell, 2005, 123, 23-35.

Leroy J., Abi-Gerges A., Nikolaev V.O., Richter W., Lechęne P., Mazet J.-L., Conti M., Fischmeister R., Vandecasteele G., Spatiotemporal dynamics of B-adrenergic cAMP signals and L-type $\mathrm{Ca}^{2+}$ channel regulation in adult rat ventricular myocytes: Role of phosphodiesterases. Circ Res, 2008, 102, 1091-1100.

Leroy J., Richter W., Mika D., Castro L.R.V., Abi-Gerges A., Xie M., Scheitrum C., Lefebvre F., Schittl J., Westenbroek R., Catterall W.A., Charpentier F., Conti M., Fischmeister R., Vandecasteele G., Phosphodiesterase 4B in the cardiac L-type $\mathrm{Ca}^{2+}$ channel complex regulates $\mathrm{Ca}^{2+}$ current and protects against ventricular arrhythmias. $J$ Clin Invest, 2011, 121, 2651-2661.

Lugnier C., Cyclic nucleotide phosphodiesterase (PDE) superfamily: a new target for the development of specific therapeutic agents. Pharmacol Therap, 2006, 109, 366-398.

Lugnier C., Muller B., Lebec A., Beaudry C., Rousseau E., Characterization of indolidansensitive and rolipram-sensitive cyclic nucleotide phosphodiesterases in canine and human cardiac microsomal fractions. J Pharmacol Exp Therap, 1993, 265, 1142-1151.

Lugnier C., Keravis T., Le Bec A., Pauvert O., Proteau S., Rousseau E., Characterization of cyclic nucleotide phosphodiesterase isoforms associated to isolated cardiac nuclei. Biochim Biophys Acta, 1999, 1472, 431-446.

Lynch M.J., Baillie G.S., Mohamed A., Li X., Maisonneuve C., Klussmann E., van Heeke G., Houslay M.D., RNA silencing identifies PDE4D5 as the functionally relevant cAMP phosphodiesterase interacting with beta -arrestin to control the PKA/AKAP79-mediated switching of the $\beta_{2}$-adrenergic receptor to activation of ERK in HEK293 cells. $J$ Biol Chem, 2005, 280, 33178-33189.

Marx S.O., Reiken S., Hisamatsu Y., Jayaraman T., Burkhoff D., Rosemblit N., Marks A.R., PKA phosphorylation dissociates FKBP12.6 from the calcium release channel (Ryanodine receptor): Defective regulation in failing hearts. Cell, 2000, 101, 365-376.

Marx S.O., Kurokawa J., Reiken S., Motoike H., D'Armiento J., Marks A.R., Kass R.S., Requirement of a macromolecular signaling complex for $\beta$-adrenergic receptor modulation of the KCNQ1-KCNE1 potassium channel. Science, 2002, 295, 496-499.

Masunaga R., Nagasaka A., Sawai Y., Hayakawa N., Nakai A., Hotta K., Kato Y., Hishida H., Takahashi H., Naka M., Shimada Y., Tanaka T., Hidaka H., Itoh M., Changes in cyclic nucleotide phosphodiesterase activity and calmodulin concentration in heart muscle of cardiomyopathic hamsters. J Mol Cell Cardiol, 2004, 37, 767-774. 
Mehats C., Andersen C.B., Filopanti M., Jin S.L.C., Conti M., Cyclic nucleotide phosphodiesterases and their role in endocrine cell signaling. Trends Endocrinol Metab, 2002, 13, 29-35.

Miller C.L., Oikawa M., Cai Y., Wojtovich A.P., Nagel D.J., Xu X., Xu H., Florio V., Rybalkin S.D., Beavo J.A., Chen Y.F., Li J.D., Blaxall B.C., Abe J., Yan C., Role of $\mathrm{Ca}^{2+} /$ calmodulin-stimulated cyclic nucleotide phosphodiesterase 1 in mediating cardiomyocyte hypertrophy. Circ Res, 2009, 105, 956-964.

Mokni W., Keravis T., Etienne-Selloum N., Walter A., Kane M.O., Schini-Kerth V.B., Lugnier C., Concerted regulation of cGMP and cAMP phosphodiesterases in early cardiac hypertrophy induced by angiotensin II. PLoS One, 2010, 5, e14227.

Mongillo M., McSorley T., Evellin S. , Sood A., Lissandron V., Terrin A., Huston E., Hannawacker A., Lohse M.J., Pozzan T., Houslay M.D., Zaccolo M., Fluorescence resonance energy transfer-based analysis of cAMP dynamics in live neonatal rat cardiac myocytes reveals distinct functions of compartmentalized phosphodiesterases. Circ Res 2004, 95, 65-75.

Mongillo M., Tocchetti C.G., Terrin A., Lissandron V., Cheung Y.F., Dostmann W.R., Pozzan T., Kass D.A., Paolocci N., Houslay M.D., Zaccolo M., Compartmentalized phosphodiesterase-2 activity blunts $\beta$-adrenergic cardiac inotropy via an NO/cGMPdependent pathway. Circ Res, 2006, 98, 226-234.

Morel E., Marcantoni A., Gastineau M., Birkedal R., Rochais F., Garnier A., Lompré A.-M., Vandecasteele G., Lezoualc'h F., The cAMP-binding protein Epac induces cardiomyocyte hypertrophy. Circ Res, 2005, 97, 1296-1304.

Movsesian M.A., Altered cAMP-mediated signalling and its role in the pathogenesis of dilated cardiomyopathy. Cardiovasc Res, 2004, 62, 450-459.

Movsesian M.A., Bristow M.R., Alterations in cAMP-mediated signaling and their role in the pathophysiology of dilated cardiomyopathy. Curr Topics Dev Biol, 2005, 68, 25-48.

Muller B., Stoclet J.-C., Lugnier C., Cytosolic and membrane-bound cyclic nucleotide phosphodiesterases from guinea pig cardiac ventricles. Eur J Pharmacol, 1992, 225, 263272.

Métrich M., Lucas A., Gastineau M., Samuel J.-L., Heymes C., Morel E., Lezoualc'h F., Exchange protein activated by cAMP (Epac) mediates B-adrenergic receptor-induced cardiomyocyte hypertrophy. Circ Res, 2008, 102, 959-965.

Nagendran J., Archer S.L., Soliman D. , Gurtu V., Moudgil R., Haromy A., St Aubin C., Webster L., Rebeyka I.M., Ross D.B., Light P.E., Dyck J.R., Michelakis E.D., Phosphodiesterase type 5 is highly expressed in the hypertrophied human right ventricle, and acute inhibition of phosphodiesterase type 5 improves contractility. Circulation, 2007, $116,238-248$.

Nikolaev V.O., Lohse M.J., Monitoring of cAMP synthesis and degradation in living cells. Physiology (Bethesda), 2006, 21, 86-92.

Nikolaev V.O., Bunemann M., Schmitteckert E., Lohse M.J., Engelhardt S., Cyclic AMP imaging in adult cardiac myocytes reveals far-reaching $\beta_{1}$-adrenergic but locally confined 
ß2-adrenergic receptor-mediated signaling. Circ Res, 2006, 99, 1084-1091.

Nikolaev V.O., Moshkov A., Lyon A.R., Miragoli M., Novak P., Paur H., Lohse M.J., Korchev Y.E., Harding S.E., Gorelik J., ß2-Adrenergic receptor redistribution in heart failure changes cAMP compartmentation. Science, 2010, 327, 1653-1657.

Oki N., Takahashi S.I., Hidaka H., Conti M., Short term feedback regulation of cAMP in FRTL-5 thyroid cells. Role of PDE4D3 phosphodiesterase activation. J Biol Chem, 2000, $275,10831-10837$.

Osadchii O.E., Cardiac hypertrophy induced by sustained $\beta$-adrenoreceptor activation: pathophysiological aspects. Heart Fail Rev, 2007, 12, 66-86.

Ostrom R.S., Violin J.D., Coleman S., Insel P.A., Selective enhancement of beta-adrenergic receptor signaling by overexpression of adenylyl cyclase type 6: Colocalization of receptor and adenylyl cyclase in caveolae of cardiac myocytes. Mol Pharmacol, 2000, 57, 10751079.

Ostrom R.S., Gregorian C., Drenan R.M., Xiang Y., Regan J.W., Insel P.A., Receptor number and caveolar co-localization determine receptor coupling efficiency to adenylyl cyclase. J Biol Chem, 2001, 276, 42063-42069.

Patrucco E., Notte A., Barberis L., Selvetella G., Maffei A., Brancaccio M., Marengo S., Russo G., Azzolino O., Rybalkin S.D., Silengo L., Altruda F., Wetzker R., Wymann M.P., Lembo G., Hirsch E., PI3Kgamma modulates the cardiac response to chronic pressure overload by distinct kinase-dependent and -independent effects. Cell, 2004, 118, 375-387.

Patrucco E., Albergine M.S., Santana L.F., Beavo J.A., Phosphodiesterase 8A (PDE8A) regulates excitation-contraction coupling in ventricular myocytes. J Mol Cell Cardiol, 2010, 49, 330-3.

Perino A., Ghigo A., Ferrero E., Morello F., Santulli G., Baillie G.S., Damilano F., Dunlop A.J., Pawson C., Walser R., Levi R., Altruda F., Silengo L., Langeberg L.K., Neubauer G., Heymans S., Lembo G., Wymann M.P., Wetzker R., Houslay M.D., Iaccarino G., Scott J.D., Hirsch E., Integrating cardiac $\mathrm{PIP}_{3}$ and cAMP signaling through a PKA anchoring function of p110gamma. Mol Cell, 2011, 42, 84-95.

Perry S.J., Baillie G.S., Kohout T.A., McPhee I., Magiera M.M., Ang K.L., Miller W.E., McLean A.J., Conti M., Houslay M.D., Lefkowitz R.J., Targeting of cyclic AMP degradation to $\beta_{2}$-adrenergic receptors by $\beta$-arrestins. Science, 2002, 298, 834-836.

Rapundalo S.T., Solaro R.J., Kranias E.G., Inotropic responses to isoproterenol and phosphodiesterase inhibitors in intact guinea pig hearts: comparison of cyclic AMP levels and phosphorylation of sarcoplasmic reticulum and myofibrillar proteins. Circ Res, 1989, 64, 104-111.

Reeves M.L., Leigh B.K., England P.J., The identification of a new cyclic nucleotide phosphodiesterase activity in human and guinea-pig cardiac ventricle. Implications for the mechanism of action of selective phosphodiesterase inhibitors. Biochem J, 1987, 241, 535541.

Rich T.C., Fagan K.A., Nakata H., Schaack J., Cooper D.M.F., Karpen J.W., Cyclic nucleotide-gated channels colocalize with adenylyl cyclase in regions of restricted cAMP 
diffusion. J Gen Physiol, 2000, 116, 147-161.

Richter W., Day P., Agraval R., Bruss M.D., Granier S., Wang Y.L., Rasmussen S.G.F., Horner K., Wang P., Lei T., Patterson A.J., Kobilka B.K., Conti M., Signaling from B1- and $ß_{2}$-adrenergic receptors is defined by differential interactions with PDE4. EMBO J, 2008, 27, 384-393.

Richter W., Jin S.L., Conti M. (). Splice variants of the cyclic nucleotide phosphodiesterase PDE4D are differentially expressed and regulated in rat tissue. Biochem J, 2005, 388, 803811.

Richter W., Xie M., Scheitrum C., Krall J., Movsesian M.A., Conti M., Conserved expression and functions of PDE4 in rodent and human heart. Basic Res Cardiol, 2011, $106,249-262$.

Rochais F., Vandecasteele G., Lefebvre F., Lugnier C., Lum H., Mazet J.-L., Cooper D.M.F., Fischmeister R., Negative feedback exerted by PKA and cAMP phosphodiesterase on subsarcolemmal cAMP signals in intact cardiac myocytes. An in vivo study using adenovirus-mediated expression of CNG channels. J Biol Chem, 2004, 279, 52095-52105

Rochais F., Abi-Gerges A., Horner K., Lefebvre F., Cooper D.M.F., Conti M., Fischmeister R., Vandecasteele G., A specific pattern of phosphodiesterases controls the cAMP signals generated by different $\mathrm{G}_{\mathrm{s}}$-coupled receptors in adult rat ventricular myocytes. Circ Res, 2006, 98, 1081-1088.

Rybin V.O., Pak E., Alcott S., Steinberg S.F., Developmental changes in $\beta_{2}$-adrenergic receptor signaling in ventricular myocytes: the role of $\mathrm{Gi}$ proteins and caveolae microdomains. Mol Pharmacol, 2003, 63, 1338-1348.

Sato N., Asai K., Okumura S., Takagi G., Shannon R.P., FujitaYamaguchi Y., Ishikawa Y., Vatner S.F., Vatner D.E., Mechanisms of desensitization to a PDE inhibitor (Milrinone) in conscious dogs with heart failure. Am J Physiol Heart Circ Physiol, 1999, 45, H1699H1705.

Saucerman J.J., Zhang J., Martin J.C., Peng L.X., Stenbit A.E., Tsien R.Y., McCulloch A.D., Systems analysis of PKA-mediated phosphorylation gradients in live cardiac myocytes. Proc Natl Acad Sci USA, 2006, 103, 12923-12928.

Schroder F., Handrock R., Beuckelmann D.J., Hirt S., Hullin R., Priebe L., Schwinger R.H.G., Weil J., Herzig S., Increased availability and open probability of single L-type calcium channels from failing compared with nonfailing human ventricle. Circulation, 1998, 98, 969-976.

Scott J.D., Santana L.F., A-kinase anchoring proteins: getting to the heart of the matter. Circulation, 2010, 121, 1264-1271.

Sette C., Conti M., Phosphorylation and activation of a cAMP-specific phosphodiesterase by the cAMP-dependent protein kinase - Involvement of serine 54 in the enzyme activation. $J$ Biol Chem, 1996, 271, 16526-16534.

Shahid M., Nicholson C.D., Comparison of cyclic nucleotide phosphodiesterase isoenzymes in rat and rabbit ventricular myocardium - Positive inotropic and phosphodiesterase inhibitory effects of Org-30029, milrinone and rolipram. Naunyn-Schmiedebergs Arch 
Pharmacol, 1990, 342, 698-705.

Shahid M., Wilson M., Nicholson C.D., Marshall R.J., Species-dependent differences in the properties of particulate cyclic nucleotide phosphodiesterase from rat and rabbit ventricular myocardium. J Pharma Pharmacol, 1990, 42, 283-284.

Simmons M.A., Hartzell H.C., Role of phosphodiesterase in regulation of calcium current in isolated cardiac myocytes. Mol Pharmacol, 1988, 33, 664-671.

Smith C.J., Huang R., Sun D., Ricketts S., Hoegler C., Ding J.Z., Moggio R.A., Hintze T.H., Development of decompensated dilated cardiomyopathy is associated with decreased gene expression and activity of the milrinone-sensitive cAMP phosphodiesterase PDE3A. Circulation, 1997, 96, 3116-3123.

Sonnenburg W.K., Mullaney P.J., Beavo J.A., Molecular Cloning of a Cyclic GMPStimulated Cyclic Nucleotide Phosphodiesterase cDNA - Identification and Distribution of Isozyme Variants. J Biol Chem, 1991, 266, 17655-17661.

Stangherlin A., Gesellchen F., Zoccarato A., Terrin A., Fields L.A., Berrera M., Surdo N.C., Craig M.A., Smith G., Hamilton G., Zaccolo M., cGMP Signals modulate cAMP levels in a compartment-specific manner to regulate catecholamine-dependent signaling in cardiac myocytes. Circ Res, 2011, 108, 929-939.

Steinberg S.F., Brunton L.L., Compartmentation of G protein-coupled signaling pathways in cardiac myocytes. Ann Rev Pharmacol Toxicol, 2001, 41, 751-773.

Stork P.J.S., Schmitt J.M. Crosstalk between cAMP and MAP kinase signaling in the regulation of cell proliferation. Trends Cell Biol, 2002, 12, 258-266.

Tasken K., Aandahl E.M., Localized effects of cAMP mediated by distinct routes of protein kinase A. Physiol Rev, 2004, 84, 137-167.

Terrenoire C., Houslay M.D., Baillie G.S., Kass R.S., The cardiac IKs potassium channel macromolecular complex includes the phosphodiesterase PDE4D3. J Biol Chem, 2009, 284, 9140-9146.

Terrin A., Di Benedetto G., Pertegato V., Cheung Y.F., Baillie G., Lynch M.J., Elvassore N., Prinz A., Herberg F.W., Houslay M.D., Zaccolo M., PGE1 stimulation of HEK293 cells generates multiple contiguous domains with different [cAMP]: role of compartmentalized phosphodiesterases. J Cell Biol, 2006, 175, 441-451.

Vandeput F., Wolda S.L., Krall J., Hambleton R., Uher L. , McCaw K.N., Radwanski P.B., Florio V., Movsesian M.A., Cyclic nucleotide phosphodiesterase PDE1C in human cardiac myocytes. J Biol Chem, 2007, 282, 32749-32757.

Verde I., Vandecasteele G., Lezoualc'h F., Fischmeister R., Characterization of the cyclic nucleotide phosphodiesterase subtypes involved in the regulation of the L-type $\mathrm{Ca}^{2+}$ current in rat ventricular myocytes. Brit J Pharmacol, 1999, 127, 65-74.

Verde I., Pahlke G., Salanova M., Zhang G., Wang S., Coletti D., Onuffer J., Jin S.L.C., Conti M., Myomegalin is a novel protein of the Golgi/centrosome that interacts with a cyclic nucleotide phosphodiesterase. J Biol Chem, 2001, 276, 11189-11198.

Vila Petroff M.G., Egan J.M., Wang X., Sollott S.J., Glucagon-like peptide-1 increases 
cAMP but fails to augment contraction in adult rat cardiac myocytes. Circ Res, 2001, 89, 445-452.

Warrier S., Ramamurthy G., Eckert R.L., Nikolaev V.O., Lohse M.J., Harvey R.D. cAMP microdomains and L-type $\mathrm{Ca}^{2+}$ channel regulation in guinea-pig ventricular myocytes. $J$ Physiol, 2007, 580, 765-776.

Wechsler J., Choi Y.H., Krall J., Ahmad F., Manganiello V.C., Movsesian M.A. (). Isoforms of cyclic nucleotide phosphodiesterase PDE3A in cardiac myocytes. J Biol Chem, 2002, 277, 38072-38078.

Weishaar R.E., Kobylarz-Singer D.C., Steffen R.P., Kaplan H.R., Subclasses of cyclic AMPspecific phosphodiesterase in left ventricular muscle and their involvement in regulating myocardial contractility. Circ Res, 1987, 61, 539-547.

Willoughby D., Cooper D.M., Organization and $\mathrm{Ca}^{2+}$ regulation of adenylyl cyclases in cAMP microdomains. Physiol Rev, 2007, 87, 965-1010.

Xiang Y., Naro F., Zoudilova M., Jin S.L., Conti M., Kobilka B., Phosphodiesterase 4D is required for $\beta_{2}$ adrenoceptor subtype-specific signaling in cardiac myocytes. Proc Natl Acad Sci USA, 2005, 102, 909-914.

Xiao R.P., Lakatta E.G., $\beta_{1}$-Adrenoceptor stimulation and $\beta_{2}$-adrenoceptor stimulation differ in their effects on contraction, cytosolic $\mathrm{Ca}^{2+}$, and $\mathrm{Ca}^{2+}$ current in single rat ventricular cells. Circ Res, 1993, 73, 286-300

Xiao R.P., Hohl C., Altschuld R., Jones L., Livingston B., Ziman B., Tantini B., Lakatta E.G., $B_{2}$-adrenergic receptor-stimulated increase in cAMP in rat heart cells is not coupled to changes in $\mathrm{Ca}^{2+}$ dynamics, contractility, or phospholamban phosphorylation. J Biol Chem, 1994, 269, 19151-19156.

Yan C., Miller C.L., Abe J., Regulation of phosphodiesterase 3 and inducible cAMP early repressor in the heart. Circ Res, 2007, 100, 489-501.

Yang J.C., Drazba J.A., Ferguson D.G., Bond M., A-kinase anchoring protein 100 (AKAP100) is localized in multiple subcellular compartments in the adult rat heart. $J$ Cell Biol, 1998, 142, 511-522.

Yang Z., Pascarel C., Steele D.S., Kornukai K., Brette F., Orchard C.H., $\mathrm{Na}^{+}-\mathrm{Ca}^{2+}$ exchange activity is localized in the T-tubules of rat ventricular myocytes. Circ Res, 2002, 91, 315322.

Zaccolo M., Pozzan T., Discrete microdomains with high concentration of cAMP in stimulated rat neonatal cardiac myocytes. Science, 2002, 295, 1711-1715. 